\title{
Online Instructors As Thinking Advisors: A Model For Online Learner Adaptation
}

\author{
Christopher Benedetti, Ph.D., Western State Colorado University, USA
}

\begin{abstract}
This article examines the characteristics and challenges of online instruction and presents a model for improving learner adaptation in an online classroom. Instruction in an online classroom presents many challenges, including learner individualization. Individual differences in learning styles and preferences are often not considered in the development and delivery of online course content. Online instructors also struggle with engaging students within the generalized environment of an online classroom, which is a consequence of the lack of learner individualization. One way to individualize the learning experience in an online classroom is to appeal to students' learning characteristics and preferences, which include learning styles, navigation behaviors, and social and environmental factors. Utilizing these characteristics and preferences, the online instructor and student can work together on a process of online learner adaption. The process includes three main components that incorporate the identified characteristics and preferences: identifying the lens, creating the map, and delivering the tool. To facilitate the process of online learner adaption, the instructor serves as a thinking advisor, assisting the students in identifying their own learning styles and preferences and how they can be adapted to optimize learning in the online classroom.
\end{abstract}

Keywords: Online Learning; Learning Styles; Navigation Behavior

\section{INTRODUCTION AND BACKGROUND}

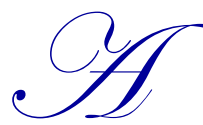

s K-12 school systems, colleges, and universities increase their offerings of online courses (Brodke \& Mruk, 2009), it is important to clearly define effective teaching and learning in an online classroom. The process of moving materials from a traditional class to an online class does not automatically replicate the same learning experience. The online instructor must utilize format-specific strategies and structures for interaction and communication with the instructional content to promote student engagement (Rovai, 2004). A common belief for increasing student engagement in learning is through instructional individualization (Santally \& Senteni, 2013). One way to individualize course content is to appeal to each student's learning characteristics and preferences, such as learning styles. Even though the concept of learning styles has been a popular topic of research studies and theoretical work in the field of education for many years (Haider, Singh, \& Triar, 2012), it remains unclear if students' learning styles and performance in online courses are linked (Halbert, Kriebel, Cuzzolino, Coughlin, \& Fresa-Dillon, 2011). Also, the practical application of individual learning preferences in the context of online course design remains a challenge (Kozub, 2010).

\section{CONCEPTUAL FRAMEWORK}

Most faculty teaching online recognize that working within the context of a web-based setting, whether it is basic information retrieval or more complex content processing, is not a simple, straightforward task (Mat-Hassan \& Levene, 2005). When assisting students working in an online course, it is important to recognize that students have individual differences that reflect prior knowledge and skills, intellectual capacity, cognitive ability, and learning preferences (Graf, Liut, \& Kinshuk, 2010). Beyond this awareness, instructors need to focus on those characteristics that can be utilized to enhance learning. Students do receive some level of individualized support in most online courses, but instructors can do more to maximize learning (Bishop \& Foster, 2011). The key is for instructors to be 
able to identify students' individual learning characteristics, learning styles and navigation behaviors, and develop strategies that engage these characteristics.

\section{Learning Styles}

One of the most commonly identified learner characteristics is learning styles. "The concept of individual learning styles holds that the individual's learning style predisposes them to acquire and process new information in unique ways" (Kozub, 2010, p. 89). By their nature, learning styles have an impact on the individual's ability to learn (Manochehri, 2008) and process knowledge (Felder, 1996). Maximum learning can occur when the individual's learning style is properly utilized. While some educators debate the role learning styles specifically play in online courses, many believe that individual learning styles should at least be acknowledged (Lu \& Chiou, 2010). A match between learning style and teaching style has been shown to be effective (Manochehri, 2008), but this is not always practical or possible in online courses. Although learning styles have not been shown to have a direct correlation to academic performance (Shih, Liu, \& Sanchez, 2013), students' belief that a course met their learning styles and preferences has been linked to overall satisfaction (Manochehri, 2008), which can have a positive, indirect effect on learning.

\section{Navigation Behavior}

Navigation behavior is a learner characteristic that is unique to an online learning environment. Navigation behavior is the ability of the learner to retrieve, follow, and link multiple forms of information within a web-based environment (Sullivan, Gnesdilow, \& Puntambekar, 2011). Successful navigation behavior is dependent upon knowledge and understanding of the information system (Mat-Hassan \& Levene, 2005) to allow the individual to find needed information quickly and be able to return easily to previous pages or links. Individuals can possess a variety of navigation behaviors based upon their prior experience working with hypertext, comfort with technology, and even their reading comprehension skills (Sullivan et al., 2011). Several studies have established a link between navigation behaviors and a student's learning style in an online environment (Bousbia, Rebai, Labat, \& Balla, 2010), which can create further variance in individual navigation behaviors.

Figure 1. Comparison between learning styles and navigation behavior in an online classroom.

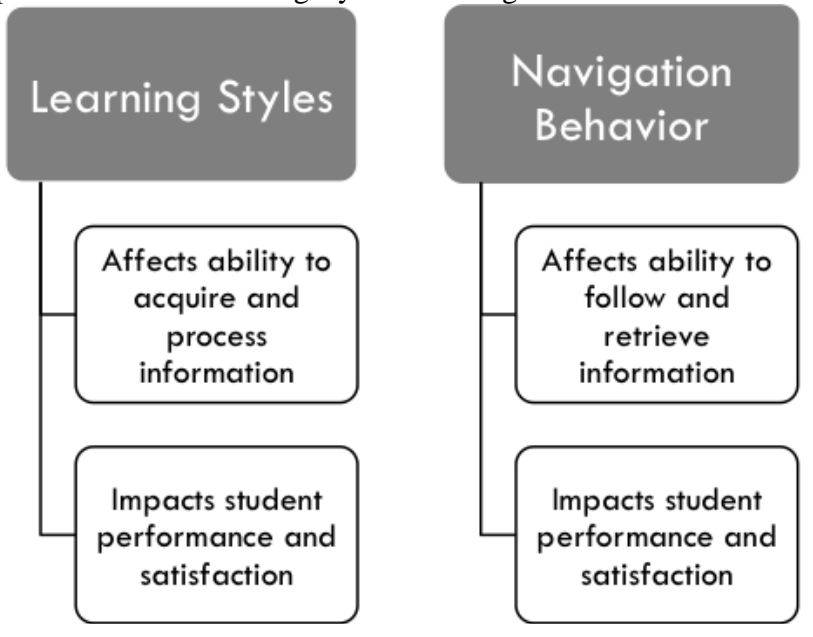

\section{DISCUSSION OF THE MODEL}

In order to maximize the learning experience for students enrolled in online courses, instructors must effectively utilize the learning characteristics of each student. In an online classroom, learner characteristics work together in a unique way to process information and build understanding. Fortunately, online instruction has embedded flexibility that allows the instructor to meet a variety of learner needs and preferences (Zacharis, 2010). Knowledge of students' learning styles and preferences can help instructors take advantage of the embedded flexibility and alter their approach and strategies in the classroom (Rogers \& McNeil, 2009). However, online 
instructors face a daunting task of organizing and representing information to meet all of their students' learner characteristics and preferences (Santally \& Senteni, 2013). Online courses must be designed before the class begins, so instructors need to somehow predict individual learner preferences prior to interacting with their students, which is impractical and inefficient. Instead, online instructors can assist students adapt to course content using their preferred learning styles. In this way, instructors become "thinking advisors," as they guide the students through their individual processing of the course.

\section{Identifying the Lens}

An individual's learning style defines how information is perceived and interpreted during the learning process (Kozub, 2010). In essence, it is the way the individual views the world when engaged in learning. In this way, a learning style becomes the lens used by the student to view and interpret instructional content. Most students are unaware or have misconceptions of their learning style (Halbert et al., 2011) or how they perceive content in an online classroom. Before any individualized course or learner adaptation can occur, the students and the instructor need to be able to accurately identify the students' individual learning style.

Figure 2. Conceptual process of facilitating individual content perception in an online classroom.

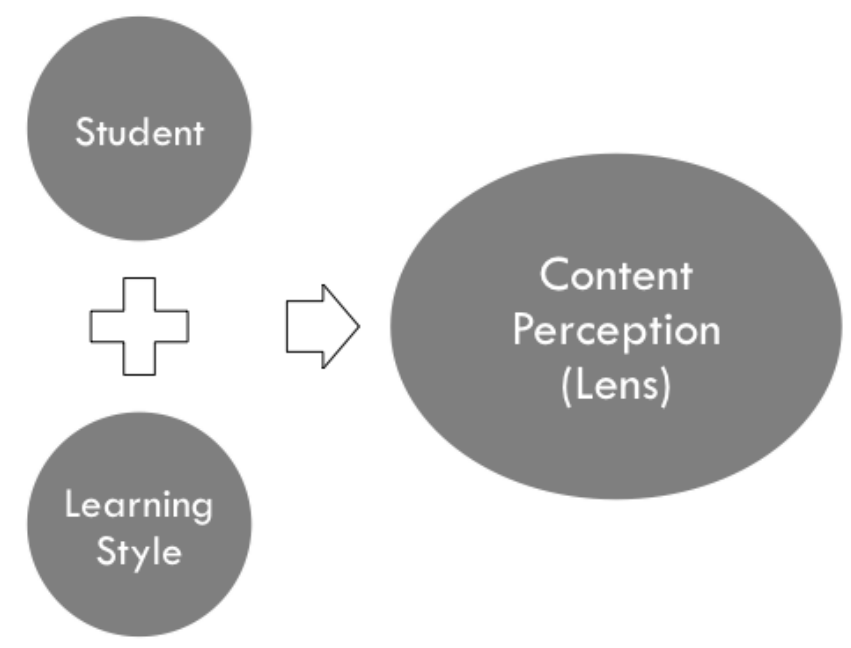

Learning style identification can occur through a variety of ways, such as a quantitative learning style questionnaire or a qualitative behavioral observation (Bousbia, Rebai, Labat, \& Balla, 2009). Although the instructor can facilitate the process of learning style identification, it is important that the students have control of the process. Students who are able to self-identify their learning style are more likely to believe the results of the identification process to be accurate (Halbert et al., 2011).

\section{Creating the Map}

Online instructors must help students move through the learning material in an online classroom (Graf et al., 2010). Without this assistance, students can become confused, disoriented, and ultimately disengaged from the course. The initial step of identifying learning styles provides a broad view of how each student will interpret course content, but it does not clearly indicate how the student will navigate the course. Although specific classifications of navigation behaviors exist (Bousbia et al., 2009), there are general practices that are beneficial to all individuals trying to navigate an online environment (Mat-Hassan \& Levene, 2005). Online instructors can create a multicomponent "map" that provides direction for interacting with the course and establishes a clear path to move between various parts of the course. 
Figure 3. Characteristics of a navigational map in an online classroom.

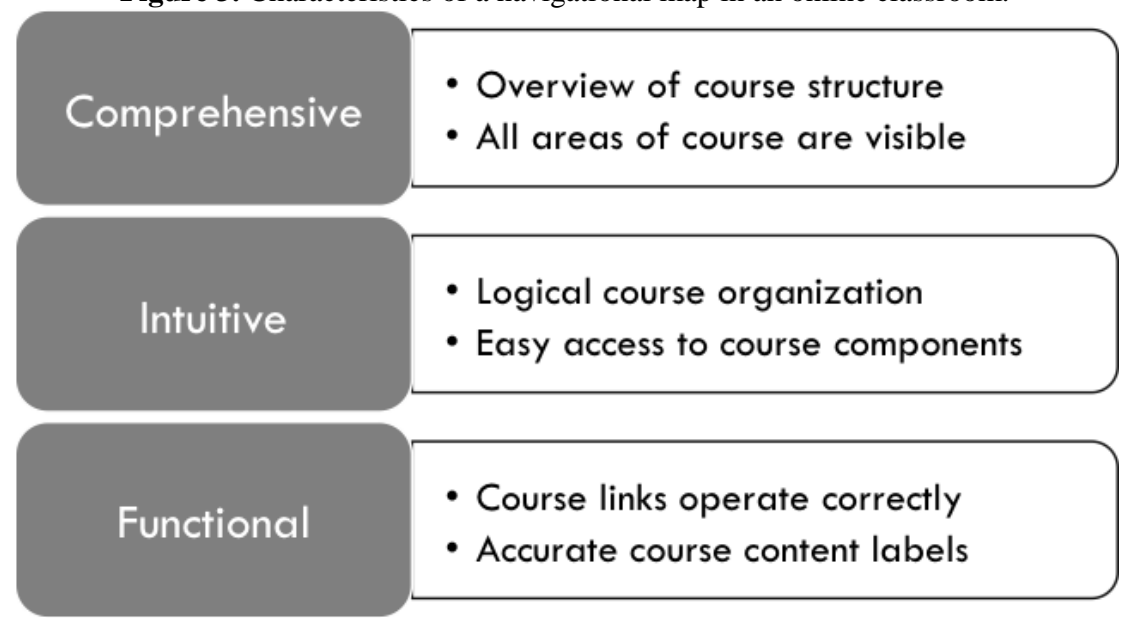

Instructors can develop an interactive, multimedia presentation that demonstrates the features of the course and highlights locations of important information. Once the student is inside the course management system, a hyperlink-based, accessible table of contents can provide a sequential trail for the students to follow, allowing them to easily follow the intended flow of the course while also being able to quickly move to other parts of the course. The presentation and table of contents will help students' navigation behavior to be more purposeful, focused, and less distracting to their learning.

\section{Delivering the Tool}

Learning style theories, and thus learning styles, are many and varied (Haider, Singh, \& Triar, 2012). As a result, it is challenging to design an online course that will meet each and all student's individual learning styles and preferences (Santally \& Senteni, 2013). If the students' learning styles are known, however, the online instructor can help students adapt their learning style to the course content. Adaption occurs through the self-analysis of various influences, such as learning environment, social preferences, and motivational factors. Students can not only adapt, but optimize, their learning by understanding the role and importance of these influences.

Figure 4. Influences on individual learning preferences in an online classroom.

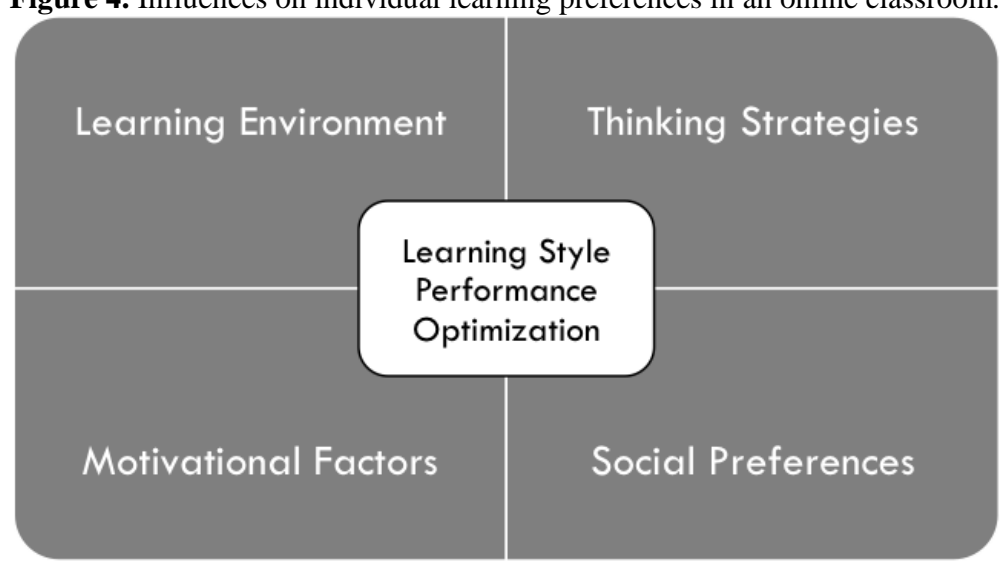

Learning style application models can further interpret, as well as facilitate, the student's individual learning style by providing examples of how the learning style can be used in specific academic situations (Cicco, 2011). Application models can be represented visually, with text, or a combination of both. Some learning style theories include application models, such as those by Dunn and Dunn (2006) and Felder and Spurlin (2005). Even with existing application models, the instructor may need to further adapt the models to fit the learner experience 
specific to the online classroom. Also, it is important that the application model reflect the learning style of the individual. A student with a learning style that is heavily dependent on abstract visualization should be given a graphical representation of the model. With learning styles identified and navigation behavior regulated, students can effectively use the strategies associated with their learning style to maximize content understanding.

\section{CONCLUSION}

In an online classroom, the student and instructor must work together towards effective and appropriate learner adaptation. Real time communication is not always available or possible in an online classroom setting, yet instructors can utilize strategies to process and facilitate students' learning preferences to promote online learner adaption. These strategies include helping students to identify their learning styles (identifying the lens), developing methods for navigating the course (creating the map), and utilizing a system for interpreting learner preferences based on learning styles (delivering the tool).

Figure 5. Model for Online Learner Adaptation.

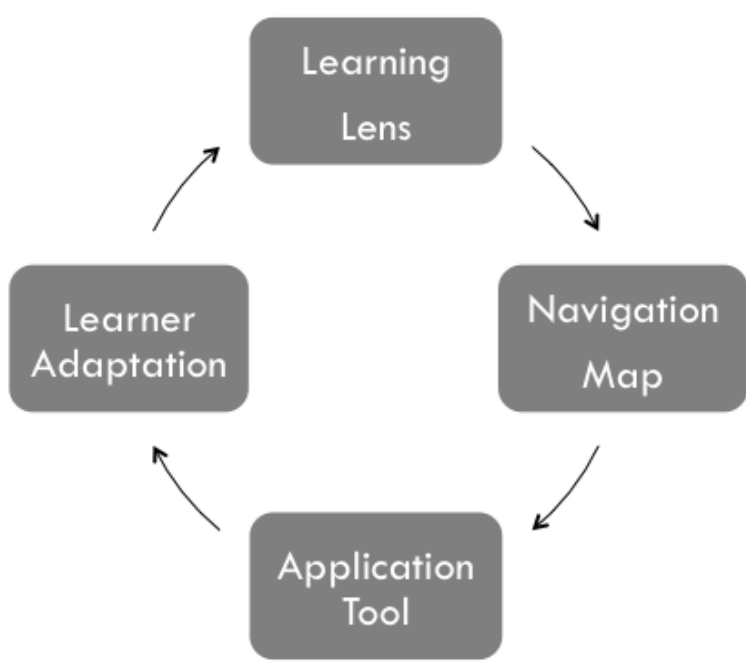

The process of learner adaptation should be cyclical to allow for variances in courses and instructors and changes to student learning styles/preferences (Daghan \& Akkoyunlu, 2012). In this model, the instructor becomes the thinking advisor to the student, as the student is in control of identifying learning styles and preferences. While the student leads the learning style and preference identification, the instructor is also responsible for development of course navigation and organization and the learning application tool. Sharing the responsibilities of online learner adaption essentially creates a partnership between student and instructor that can ultimately lead to better overall learning outcomes, which should be the goal of all online courses.

\section{AUTHOR'S NOTE}

This paper was presented at the 2014 Clute Institute International Academic Conference on January 1-4, 2014 in Orlando, Florida.

\section{AUTHOR INFORMATION}

Dr. Christopher Benedetti currently serves as an Assistant Professor of Educational Leadership at Western State Colorado University. Dr. Benedetti holds three degrees in education, including a Ph.D. in Leadership in Education from Barry University. Dr. Benedetti has spent over 15 years in the field of K-12 education, including working as a teacher, principal, and consultant. Dr. Benedetti has also presented at several state and national conferences covering topics on school leadership, teacher development, and effective instruction. E-mail: cbenedetti@western.edu 


\section{REFERENCES}

Bishop, C., \& Foster, C. (2011). Thinking styles: Maximizing online supported learning. Journal of Educational Computing Research, 44(2), 121-139.

Bousbia, N., Rebai, I., Labat, J., \& Balla, A. (2009). Analysing the relationship between learning styles and navigation behaviour in web-based educational systems. Knowledge Management \& E-Learning: An International Journal, 2(4), 400-421.

Bousbia, N., Rebai, I., Labat, J., \& Balla, A. (2010). Learners' navigation behavior identification based on trace analysis. User Model User-Adap Inter, 20, 455-494.

Brodke, M., \& Mruk, C. (2009). Crucial components of online teaching success: A review and illustrative case study. AURCO Journal, 32, 187-205.

Cicco, G. (2011). Maximizing the online learning experience: Suggestions for educators and students. i-manager's Journal on School Educational Technology, 7(1), 1-6.

Daghan, G., \& Akkoyunlu, B. (2012). An examination through conjoint analysis of the preferences of students concerning online learning environments according to their learning styles. International Education Studies, 5(4), 122-138.

Dunn, R., \& Dunn, K. (2006). Dunn \& Dunn model--English. International Learning Styles Network. Retrieved from www.ilsa-learning-styles.com.

Felder, R. (1996). Matters of style. ASEE Prism, 6(4), 18-23.

Felder, R., \& Spurlin, J. (2005). Applications, reliability, and validity of the Index of Learning Styles. International Journal of Engineering Education, 21(1), 103-112.

Graf, S., Liut, T., \& Kinshuk, C. (2010). Analysis of learners' navigational behaviour and their learning styles in an online course. Journal of Computer Assisted Learning, 26, 116-131.

Haider, M., Singh, M., \& Triar, U. (2012). An investigation of any correlation amongst cognitive styles, cognitive traits, and performance of learners for developing a generalized semantic framework for adaptive online learning system. International Journal of Computer Science Issues, 9(3), 241-245.

Halbert, C., Kriebel, R., Cuzzolino, R., Coughlin, P., \& Fresa-Dillon, K. (2011). Self-assessed learning style correlates to use of supplemental learning materials in an online course management system. Medical Teacher, 33, 331-333.

Kozub, R. (2010). An ANOVA analysis of the relationships between business students' learning styles and effectiveness of web based instruction. American Journal of Business Education, 3(3), 89-98.

Lu, H., \& Chiou, M. (2010). The impact of individual differences on e-learning system satisfaction: A contingency approach. British Journal of Educational Technology, 41(2), 307-323.

Manochehri, N. (2008). Individual learning style effects on student satisfaction in a web-based environment. International Journal of Instructional Media, 35(2), 221-228.

Mat-Hassan, M., \& Levene, M. (2005). Associating search and navigation behavior through log analysis. Journal of the American Society for Information Science and Technology, 56(9), 913-934.

Rogers, P., \& McNeil, K. (2009). Student learning styles and online course performance: An empirical examination of student success in a web-based management course. Business Education Digest, 18, 1-15.

Rovai, A. (2004). A constructivist approach to online college learning. Internet and Higher Education, 7, 79-93.

Santally, M., \& Senteni, A. (2013). Effectiveness of personalized learning paths on students learning experiences in an e-learning environment. European Journal of Open, Distance and e-Learning, 16(1), 36-52.

Shih, Y., Liu, Y., \& Sanchez, C. (2013). Online learning style preferences: An analysis of Taiwanese and USA learners. The Turkish Online Journal of Educational Technology, 12(4), 140-152.

Sullivan, S., Gnesdilow, D., \& Puntambekar, S. (2011). Navigation behaviors and strategies used by middle school students to learn from a science hypertext. Journal of Educational Media and Hypermedia, 20(4), 387-423.

Zacharis, N. (2010). The impact of learning styles on student achievement in a web-based versus an equivalent faceto-face course. College Student Journal, 44(3), 591-597. 